\title{
Once Upon a Time - A Personal View on Episodes in Leukemia Research in Germany, and Beyond
}

P. Gaynon

Bibliography DOI http://dx.doi.org/ 10.1055/s-0033-1337971 Klin Padiatr 2013; 225

(Suppl. 1): S5

(C) Georg Thieme Verlag KG Stuttgart · New York ISSN 0300-8630

\section{Correspondence}

\section{Prof. Paul Gaynon, MD}

Children's Hospital Los Angeles Pediatric Hematology/Oncology Los Angeles CA 90027 USA

Tel.: + 1/323/3615600 Fax: $+1 / 323 / 3613661$ PGaynon@chla.usc.edu
Once upon a time, the various committees charged with improving the outcome of children with acute lymphoblastic leukemia around the world worked in isolation, learning of each others' work only at the few internationally attended meetings or in English language publications. Investigators were jealous of primacy and suspicious of others.

In 1980, the Children's Cancer Study Group later the Children's Cancer Group (CCG) learned of the work of Professor Hansjörg Riehm, Günter Henze, and the BFM Group in Germany. We believed the "M" in BFM stood for Munich at that time. The story goes that my friend Jim Nachman and I came to work about the same time that day but I beat him by half a step - which was hard because Jim was quick both mentally and physically - and Edward Baum, our mentor, handed me a Xeroxed copy of the BFM 76/79 protocol "auf Deutsch." Thanks to the skill and patience of my high school German teachers, Herr Huber and Herr Brink, I more or less translated the regimen into English, which really was not all that hard.

Archie Bleyer asked me to chair the pilot. Between 1981 and 1983, CCSG enrolled 213 patients on the 193p study - a pilot based on BFM 76. We found ourselves giving therapy in the face of low peripheral counts where past practice required delay. Initially, we faced a substantial death rate - over 5\% in Protocol II or what we call 'Delayed Intensification'. Now the death rate is below $0.5 \%$. CCSG had a practice where every trial was presented to the $30+$ principle investigators at each Group meeting. A majority vote could terminate a study. The day came when Anna Meadows moved that the study be closed because of unacceptable toxicity. Judith Chessells added her strong voice. A much younger me with help from Nasrollah Shahidi had to stand up to these 2 distinguished ladies, both of whom I hold in highest esteem. It came to a vote and we won but made some changes in Delayed Intensification - limiting the number of anthracycline doses to three and the weeks of dexamethasone to 3. Outcomes looked substantially better than past CCSG trials, an impression that was confirmed in the subsequent randomized CCG-106 and CCG-123 studies. In early 1988 , I had a chance to present our data in Münster (Germany) right next to the frozen River Aa. Coming from Wisconsin, the temperature was no challenge. Dr. G. Denman Hammond and I had the last 2 speaking slots. The night before, Dr. Hammond asked me if I had prepared my remarks. I told him that I had a timed 12 min talk, memorized like a Bar Mitzvah speech. He told me that he would work on his remarks when he got back to his room. Dr. Hammond spoke first. He talked and he talked. About 30 min later, Prof. Riehm stood up and waved his arms. "Eine halbe Stunde!" he called. Dr. Hammond looked at him curiously, waved back, and spoke a second $30 \mathrm{~min}$. I had the opportunity to address an empty auditorium.

In 1988, the ALL Strategy Group, chaired by Michael Trigg, was formulating plans for the second generation of BFM-based studies. The results from David Tubergen's CCG-105 study were not final but in those innocent days, we were allowed to see preliminary results that suggested that post induction intensification was more important than intensified induction. Jim Nachman and our ALL Strategy Group constructed our Augmented BFM regimen - introducing longer and stronger post induction intensification. The success of Jim's study is well known. The current COG studies, AALL1131 and AALL0932, represent the sixth generation of BFM-based studies.

In 1990, the Medical Research Council of Great Britain hosted a working group meeting in Oxford for the meta-analysis project. I represented CCSG. Our friends in the Pediatric Oncology Group were suspicious that too close collaboration might foster group-think and squelch creativity. We teased that they feared that others might steal their secrets while we in CCSG feared we had no secrets worth stealing. Again, I had my timed 12 min talk, which thanks to interruptions and intensive cross examination by the expert attendees took more than $2 \mathrm{~h}$ to complete. Our obligation to our patients requires us to know the best and strive to do better.

In the 1990's, Jim Nachman was the first CCSG member to attend the I-BFM Meetings, many more joined later on. Jim's endless cheerful energy and eagerness to fly any place any time built trust and communication among pediatric investigators world-wide.

Jim Nachman, Giuseppe Masera, Martin Schrappe, Ching-Hon Pui and I had lunch at the Hotel Victoria in Montevideo at the XXVII ${ }^{\text {th }}$ meeting of SIOP in Montevideo, Uruguay, in 1995. We launched the productive Ponte-di-Legno Working Group, which has now had some 13 meetings and laid the groundwork for the first EuropeanNorth American clinical collaborations in $\mathrm{Ph}+$ ALL and in novel immunotherapy (blinatumomab) currently underway. 